\title{
PERANCANGAN MEDIA PANDUAN WISATA ALAM DAN CAGAR BUDAYA BANYUWANGI
}

\author{
Nicky Septiani Gunawan, \\ Benny Rahmawan Noviadji, \\ Arjuna Bangsawan. \\ Institusi Informatika Indonesia (IKADO), Surabaya. \\ nickygunawan5@gmail.com
}

\begin{abstract}
Abstrak
Kabupaten Banyuwangi merupakan kabupaten yang memiliki Objek Daya Tarik Wisata (ODTW) yang sangat beragam. Sebagai Kabupaten yang memiliki kekayaan objek wisata, Banyuwangi memiliki permasalahan dalam media yang tidak mampu memaksimalkan buku panduan wisata dan media promosi sebagai media pengenalan, panduan dan promosi, sehingga persentase wisatawan domestik dan mancanegara mengalami peningkatan yang fluktuatif dan kurang dikenal oleh wisatawan. Media yang mengusung tentang objek wisata Banyuwangi juga susah didapat dan jarang ditemukan. Berdasarkan dari permasalahan tersebut, maka tujuan dari perancangan ini adalah sebagai media praktis untuk mengenalkan objek wisata alam dan cagar budaya Banyuwangi, serta memberikan pengetahuan dan wawasan kekayaan wisata Banyuwangi. Metode pengumpulan data yang digunakan dalam perancangan ini bersifat kualitatif dan kuantitatif. Pengumpulan data primer dilakukan dengan metode wawancara mendalam, observasi dan kuesioner. Sedangkan pengumpulan data sekunder dilakukan dengan metode dokumentasi, kepustakaan dan penggalian data dari sumber-sumber yang terdapat di internet. Dengan adanya perancangan ini diharapkan Kabupaten Banyuwangi dapat memiliki media panduan wisata alam dan cagar budaya yang lebih informatif, praktis dan menarik sebagai media panduan, pengenalan serta promosi sehingga mampu menarik perhatian wisatawan domestik dan mancanegara, serta mampu meningkatkan persentase pengunjung objek wisata Banyuwangi.
\end{abstract}

Katakunci: Fotografi, Buku panduan, Buku grafis.

\begin{abstract}
Banyuwangi is a district that has the attraction of Tourism that are very diverse. As a district that has a wealth of attractions, Banyuwangi has a problem in the media who are not able to maximize tourist guide books and media campaign as media recognition, guidance and promotion, so that the percentage of domestic and foreign tourists increased volatile, and less well known by tourists. Media that carries about attractions Banyuwangi also hard to come
\end{abstract}


by and are rarely found. Based on these problems, then the purpose of this scheme is as practical media to introduce the attraction of natural and cultural heritage Banyuwangi, as well as providing a wealth of knowledge and insight Banyuwangi travel. Data collection methods used in this design are qualitative and quantitative. Primary data collection is done by in-depth interviews, observation, and questionnaires. While secondary data collection is done by the method of documentation, literature, and extracting data from sources that are on the internet. Given this design, it is expected Banyuwangi can have media travel guides to nature and cultural heritage that are more informative, practical and attractive. The introduction and promotion is to attract the attention of domestic and foreign tourists, and is able to increase the percentage of visitor attractions Banyuwangi.

Keywords: Photography, Guide book, Graphic book.

\section{PENDAHULUAN}

Indonesia memiliki potensi wilayah yang luas dengan daya tarik wisata yang cukup besar, banyaknya keindahan alam, aneka warisan sejarah budaya dan kehidupan masyarakat, terutama wilayah Kabupaten Banyuwangi. Kabupaten Banyuwangi merupakan Kabupaten terluas di Jawa Timur yang berada di ujung timur Pulau Jawa. Wilayah Kabupaten Banyuwangi membentang dari dataran tinggi hingga dataran rendah yang mempunyai daya potensi kekayaan sumber daya alam. Kabupaten Banyuwangi mempunyai Obyek Daya Tarik Wisata (ODTW) yang sangat beragam. Terdapat objek wisata berupa pantai/ laut, pegunungan/ gunung, dan air terjun. Berdasarkan pada keanekaragaman aset wisata yang lebih dominan ke arah "Natural Tourism" maka pada pengembangan pariwisata yang direkomendasikan adalah "ECOTOURISM" yaitu pengembangan wisata yang berwawasan lingkungan (Buku Rencana Induk Pengembangan Wisata Alam Kabupaten Banyuwangi hal 5-1, penetapan struktur pengembangan wisata alam).

Kabupaten Banyuwangi memiliki luas sekitar 5.782,50 km2. Wilayahnya cukup beragam, dari dataran rendah hingga pegunungan. Kawasan perbatasan dengan Kabupaten Bondowoso terdapat rangkaian dataran tinggi. Bagian selatan terdapat perkebunan peninggalan sejak zaman Hindia Belanda. Pantai timur Banyuwangi (Selat Bali) merupakan salah satu penghasil ikan terbesar di Jawa Timur. Kabupaten Banyuwangi terdiri atas 24 kecamatan yang dibagi lagi atas 
sejumlah desa dan kelurahan. Kabupaten Banyuwangi memiliki banyak objek wisata alam seperti: Kawah Ijen, Pantai Boom, Pantai Plengkung, Pantai Rajegwesi, Pulau merah, Watu Dodol, Teluk Hijau, Pantai Lampon, Pantai Blimbingsari, Rawa Bayu, Tabuhan Island, Air Terjun Rider, Wisata Osing.

Berdasarkan laman www.jpnn.com (2014) Kabupaten Banyuwangi telah memiliki Peraturan Daerah (Perda) tentang Perlindungan Cagar Budaya. DPRD Banyuwangi telah mengesahkan Perda tersebut, Bupati Banyuwangi Abdullah Azwar Anas mengatakan bahwa Perda cagar budaya mengatur tentang perlindungan benda, bangunan, dan lingkungan yang memiliki nilai sejarah serta menunjukkan identitas keaslian Banyuwangi. Dilansir dari laman www.travel.kompas.com (2013) oleh Rachmawati menyatakan bahwa hasil inventarisasi yang dilakukan, Banyuwangi mempunyai sebaran cagar budaya yang cukup banyak yang berada dalam beberapa titik kecamatan. Di Kecamatan Muncar terdapat Ompak Songo, situs Gumuk Klinting, situs Gumuk Mas, situs Gumuk Banteng, makam Adi Patih Gringsing dan situs Watu Kebo. Ada juga situs Macan Putih di Kecamatan Kabat dan di Kecamatan Songonjuruh terdapat situs Watu Kalasan, situs Watu Jaran dan situs Watu Lumpang

Dari penelitian berupa wawancara dan pembagian kuesioner yang telah dilakukan serta melihat fenomena dan permasalahan yang terjadi dapat ditemukan inti permasalahan sebagai berikut: a) Peningkatan grafik pengunjung objek wisata Banyuwangi yang fluktuatif; c) Kurang luasnya pengetahuan para wisatawan domestik maupun mancanegara akan kekayaan objek wisata alam dan cagar budaya di Banyuwangi; d) Calon wisatawan kurang tahu akan buku panduan wisata yang dimiliki Banyuwangi; e) Buku panduan wisata Banyuwangi memiliki tampilan visual dan konten yang kurang; f) Media yang mengusung tentang objek wisata Banyuwangi susah didapat dan jarang ditemukan.

Berdasarkan latar belakang di atas maka diperlukan pengembangan pariwisata di Banyuwangi dengan cara memberikan informasi tentang objek wisata alam dan cagar budaya kepada para wisatawan domestik dan mancanegara melalui media panduan wisata yang terbuka dan jelas. Tujuan dari pembuatan media panduan wisata ini adalah sebagai media praktis untuk mengenalkan objek wisata 
alam dan cagar budaya Banyuwangi, serta memberikan pengetahuan dan wawasan kekayaan wisata Banyuwangi.

\section{KAJIAN TEORI}

\section{Teori Pariwisata}

Indonesia sebegai negara yang berkembang, memiliki potensi dibidang pariwisata sebagai salah satu sektor untuk meningkatkan pendapatan negara. Pariwisata kini telah berkembang sesuai dengan tujuan pemerintah untuk memajukan pariwisata. Menurut Yoeti (1996: 113) pariwisata merupakan perjalanan yang dilakukan dari suatu tempat ke tempat lain dan dalam bahasa Inggris disebut dengan istilah "Tour". Sejalan dengan Yoeti menurut Goeldner (1999: 14) dalam bukunya Tourism Principles, Practices, Philosophies menjelaskan bahwa Pariwisata adalah susunan dari aktivitas, pelayanan, dan industri yang menawarkan pengalaman perjalanan seperti: transportasi, akomodasi, mendirikan toko makanan dan minuman, fasilitas dan pelayanan kesehatan yang berguna untuk perorangan maupun kelompok yang sedang mengadakan perjalanan keluar dari rumah.

\section{Teori Wisata alam dan Cagar budaya}

Wisata alam adalah kegiatan rekreasi dan pariwisata yang memanfaatkan potensi alam untuk menikmati keindahan alam, baik yang masih alami atau sudah ada usaha budidaya. Dalam melakukan wisata alam kita harus melestarikan area yang masih alami, memberi manfaat secara ekonomi dan mempertahankan keutuhan budaya masyarakat setempat, sehingga bisa menjadi daerah wisata. Supaya daerah tersebut memiliki potensi wisata yang dilengkapi dengan fasilitas pendukung seperti alat transportasi atau penginapan. Hal ini sejalan dengan aturan wisata alam menurut Undang-Undang No 5 tahun 1990 tentang Konservasi Sumber Daya Alam Hayati dan Ekosistemnya, Taman Wisata Alam adalah kawasan pelestarian alam yang terutama dimanfaatkan untuk pariwisata dan rekreasi alam. Sedangkan kawasan konservasi sendiri adalah kawasan dengan ciri khas tertentu, baik di darat maupun di perairan yang mempunyai sistem penyangga kehidupan, pengawetan keanekaragaman jenis tumbuhan dan satwa, serta pemanfaatan secara lestari sumber daya alam hayati dan ekosistemnya. 
Sedangkan pengertian cagar budaya menurut Undang-Undang Republik Indonesia Nomor 11 Tahun 2010 adalah warisan budaya bersifat kebendaan berupa benda cagar budaya, bangunan cagar budaya, struktur cagar budaya, situs cagar budaya dan kawasan cagar budaya di darat dan/atau di air yang perlu dilestarikan keberadaannya karena memiliki nilai penting bagi sejarah, ilmu pengetahuan, pendidikan, agama, dan kebudayaan melalui proses penetapan.

\section{METODE PENELITIAN}

Data diperoleh dari berbagai sumber secara absah yang dapat mendukung dalam proses pembuatan media buku panduan wisata. Pencarian data dilakukan melalui metode sebagai berikut: a) Mengidentifikasi fenomena dan problematika; b) Studi eksisting dan studi kompetitor serta komparator. Studi eksisting dilakukan terhadap buku yang berjudul Panduan Wisata Banyuwangi dan Daya Tarik Wisata Banyuwangi. Studi kompetitor dilakukan terhadap buku yang berjudul Wisata Kota Tua Jakarta, Wisata NTT Hidden Parradise dan Panduan Wisata Belanja Jogja. Studi komparator dilakukan terhadap buku yang berjudul The Real Australia dan Thaliand c) Hasil wawancara dengan pihak Dinas Kebudayaan dan Pariwisata Kabupaten Banyuwangi, serta masyarakat Kabupaten Banyuwangi; d) Studi literatur dan teori yang berhubungan dengan penelitian; e) Hasil dari polling dan kuesioner untuk mengetahui keinginan audiens serta menemukan permasalahan.

\section{HASIL DAN PEMBAHASAN}

Proses perancangan elemen grafis yang akan digunakan dalam media buku panduan wisata alam dan cagar budaya Kabupaten Banyuwangi diawali dengan pencarian referensi visual yang dapat mencerminkan identitas Banyuwangi seperti tari gandrung, batik gajah oling dan kesenian barong/ patung barong kemiren. Setelah melalui proses seleksi maka terpilihlah motif batik gajah oling yang akan dikembangkan dalam bentuk elemen grafis melalui proses sketsa dan digitalisasi karena batik gajah oling tidak hanya mengedepankan estetika namun juga menggambarkan kekuatan yang tumbuh dalam jati diri masyarakat Kabupaten Banyuwangi. Batik gajah oling juga sudah dikenal di Nusantara, selain itu motif batik gajah oling juga sangat mudah divektorkan. 

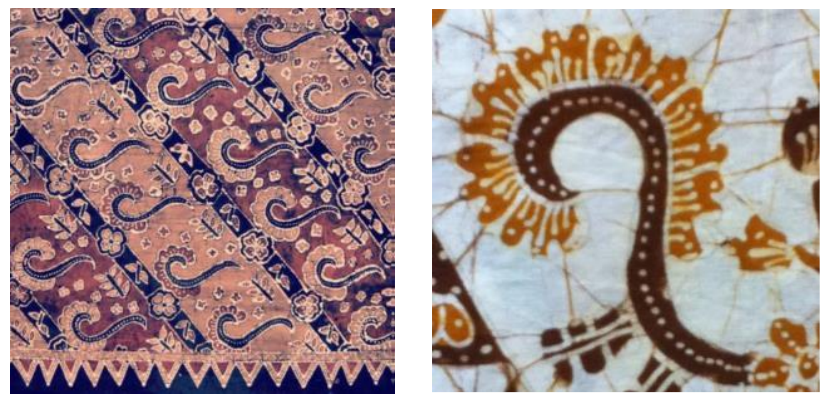

Gambar 1. Batik gajah oling Banyuwangi

Sumber: wilwatiktamuseum.wordpress.com diunduh pada tanggal 15 Desember 2014

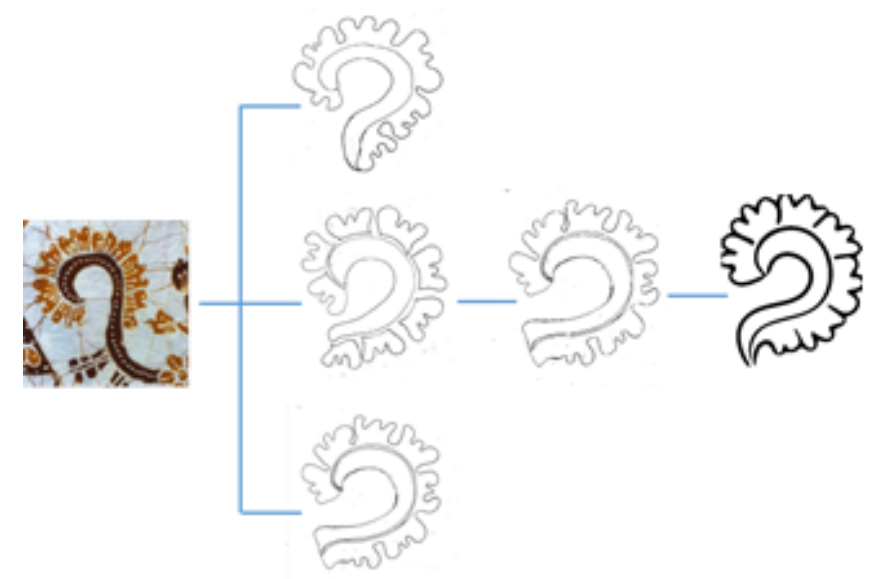

Gambar 2. Tahap ke-1 hingga tahap ke-3 proses desain elemen grafis, sedangkan gambar pada ujung kanan adalah desain final. Sumber: Dokumentasi penulis

Warna yang digunakan dalam elemen grafis adalah pengembangan warna hijau pada logo Banyuwangi yang mencerminkan identitas Banyuwangi, netral, dan juga menggunakan warna earthy (sesuai dengan konsep).

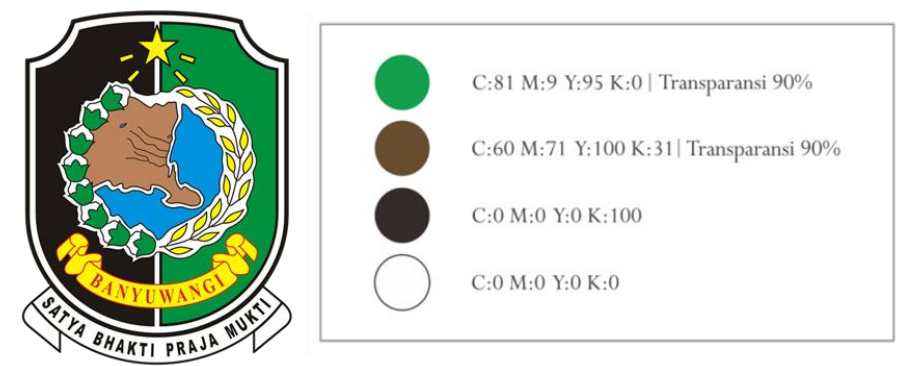

Gambar 3. Logo Banyuwangi dan penerapan warna elemen grafis. Sumber: http://logo-vectorcdr.blogspot.co.id/2015/11/logo-kabupatenbanyuwangi-vector.html diunduh tanggal 15 Desember 2014 


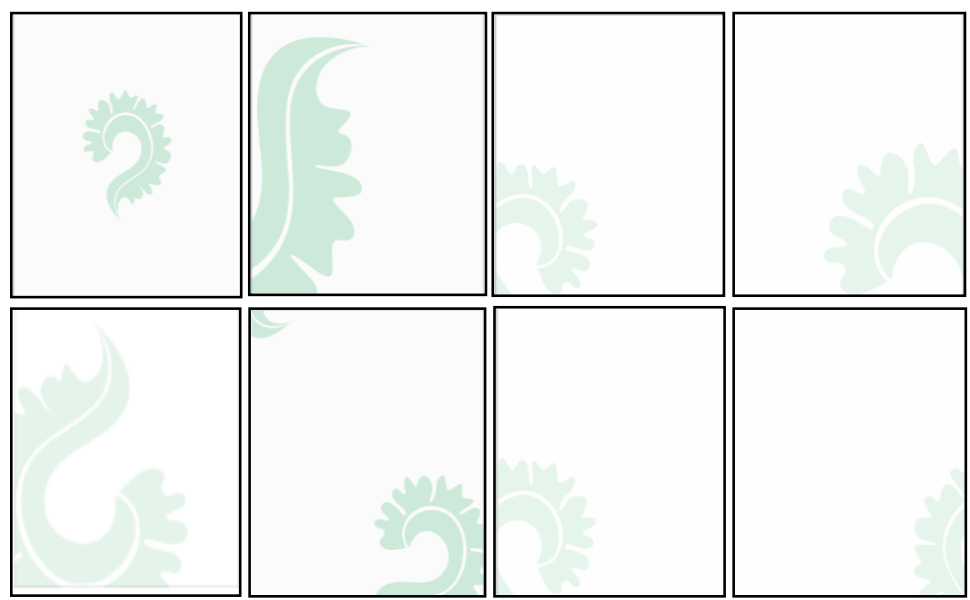

Gambar 4. Penerapan bentuk elemen grafis.

Sumber: Dokumentasi penulis

Setelah proses pembuatan elemen grafis maka pembuatan sketsa desain cover dilakukan melalui beberapa tahap seleksi. Cover didesain sesuai dengan konsep yang telah ditentukan, seperti: cover yang simpel dan penggunaan bentuk grafis yang fleksibel. Setelah tahap sketsa dilakukan proses seleksi dan terpilih 12 sketsa yang akan dikembangkan dalam proses digitalisasi. Dalam bentuk digital terpilihlah 2 desain cover yang akan dikembangkan menjadi desain cover buku panduan wisata alam dan cagar budaya Banyuwangi.

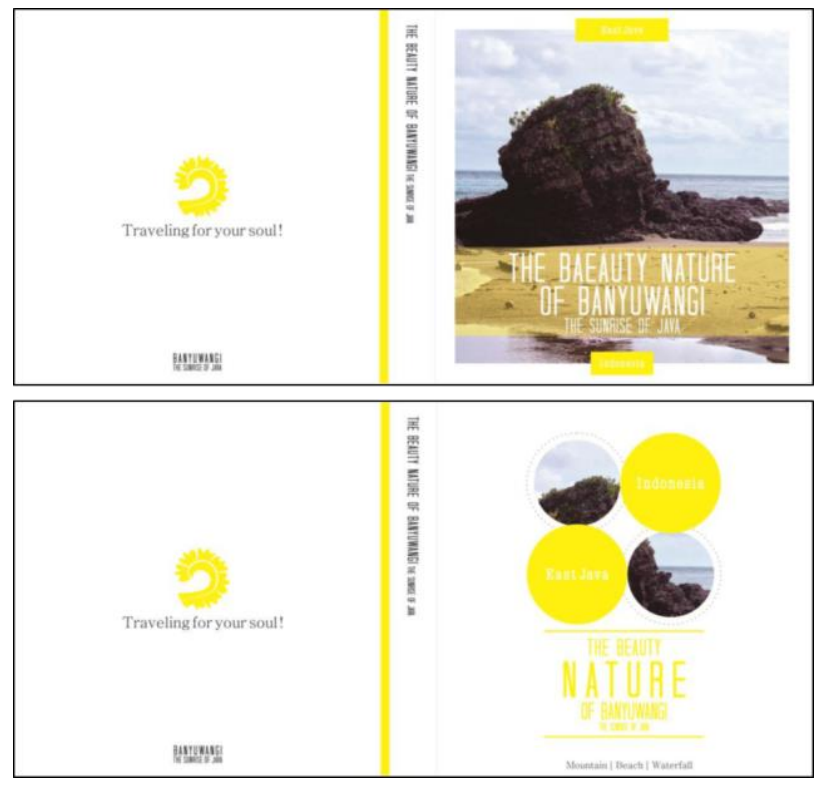

Gambar 5. Desain cover terpilih.

Sumber: Dokumentasi penulis 
Setelah terpilih 2 desain cover maka proses revisi desain pun dilakukan demi mendapat hasil desain yang terbaik dan sesuai dengan konsep, kemudian teripilih satu desain cover final.

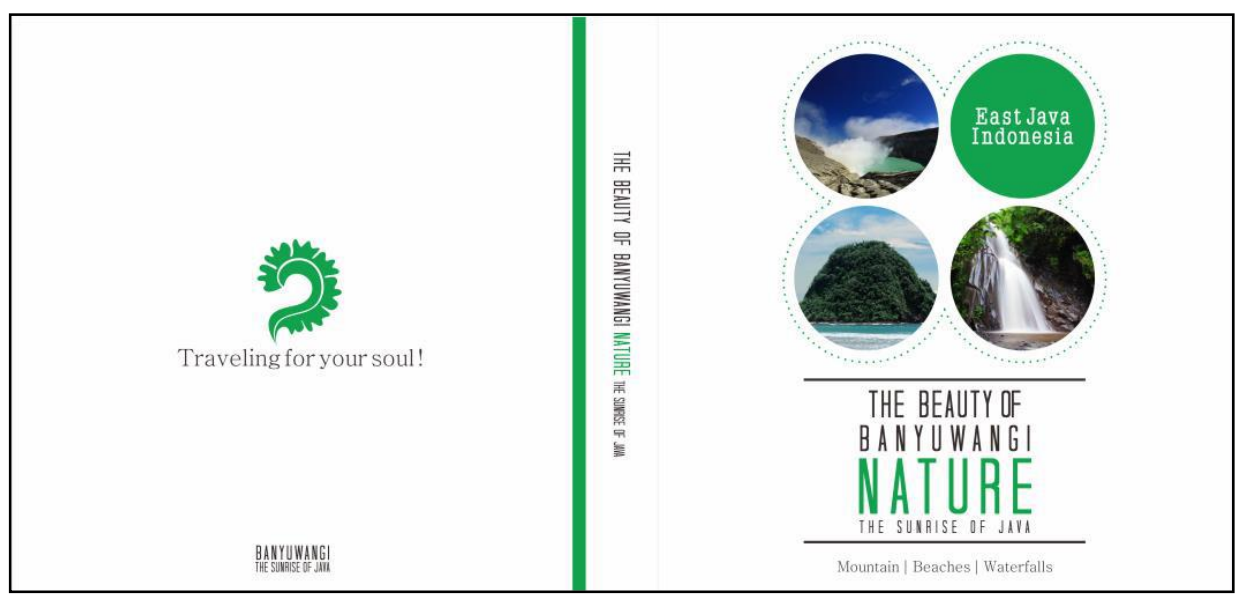

Gambar 6. Desain final cover buku panduan wisata alam. Sumber: Dokumentasi penulis

Desain cover pada buku panduan wisata alam juga diterapkan pada buku panduan wisata cagar budaya. Hal tersebut dilakukan agar desain media panduan wisata memiliki desain yang saling terkait/ berkesinambungan. Terjadi perubahan pada foto dan teks pada cover serta perubahan warna pada elemen grafis yang diterapkan. Warna yang diterapkan pada buku panduan wisata cagar budaya adalah warna earthy yang sesuai dengan konsep.

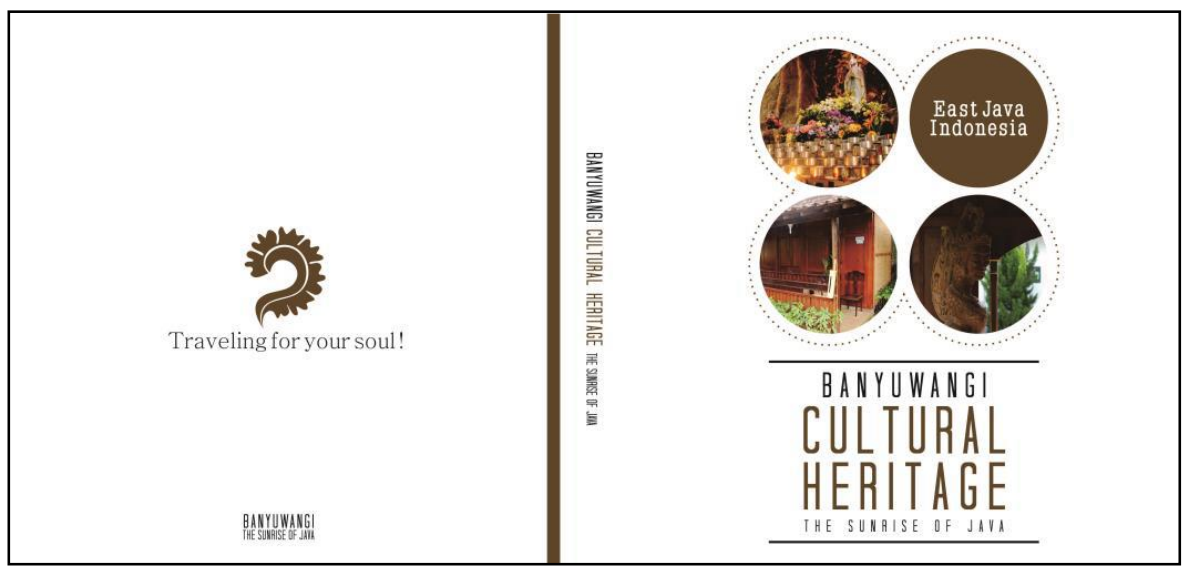

Gambar 7. Desain final cover buku panduan wisata cagar budaya. Sumber: Dokumentasi penulis 
Setelah melalui berbagai proses perancangan, presentasi dan revisi maka terpilih desain final untuk media panduan wisata alam dan cagar budaya. Media utama yang terdiri dari: buku panduan wisata alam, buku panduan wisata cagar budaya dan e-book yang menggunakan teknik fotografi. Media pendukung yang terdiri dari: peta, pembatas buku, packaging, paper bag, vip card. Media promosi terdiri dari: brosur, poster, dan $k$ banner. Merchandise yang terdiri dari stiker, ballpoint, compass keychain, pin, mini bag, kaos, tumbler dan topi.

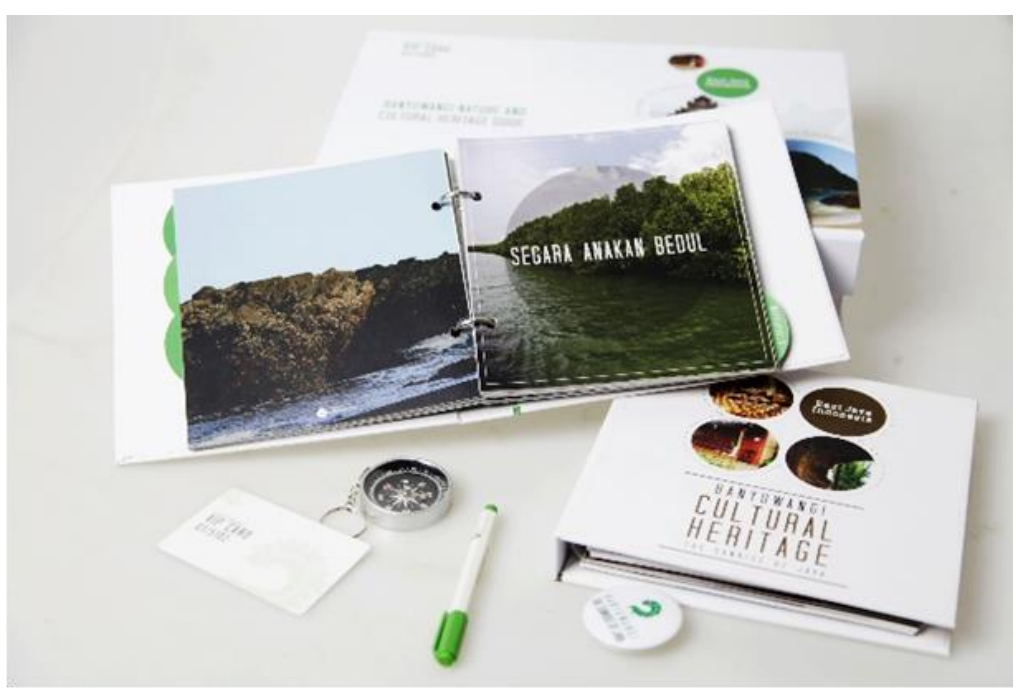

Gambar 8. Desain final buku panduan wisata alam dan cagar budaya. Sumber: Dokumentasi penulis

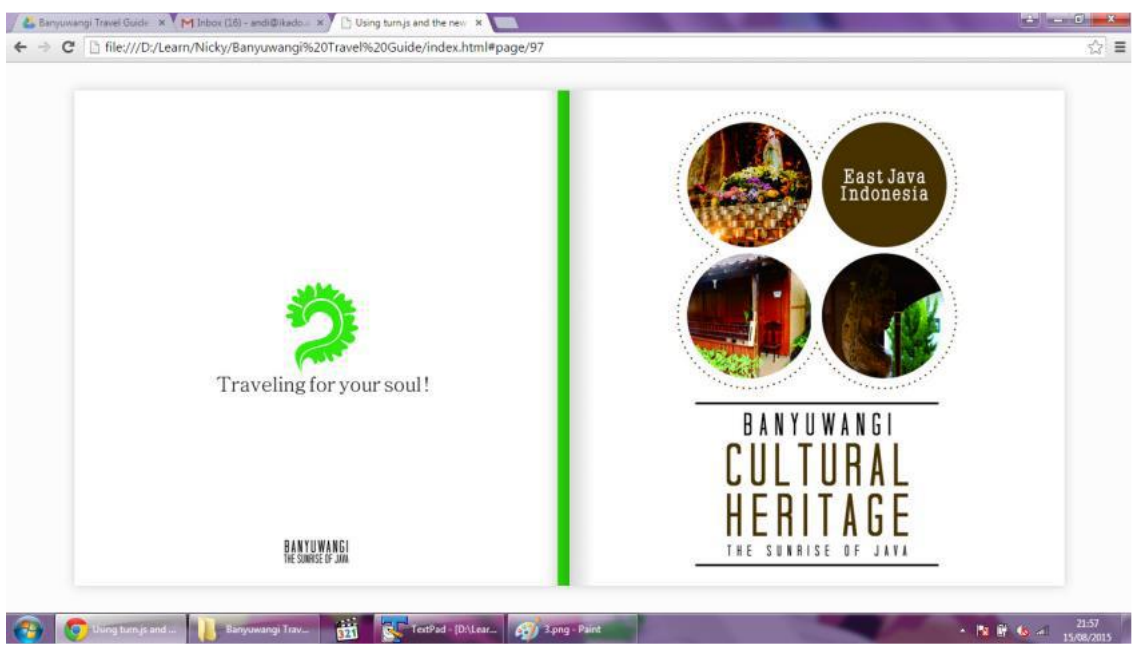

Gambar 9. Desain final $\boldsymbol{e}$-book

Sumber: Dokumentasi penulis 


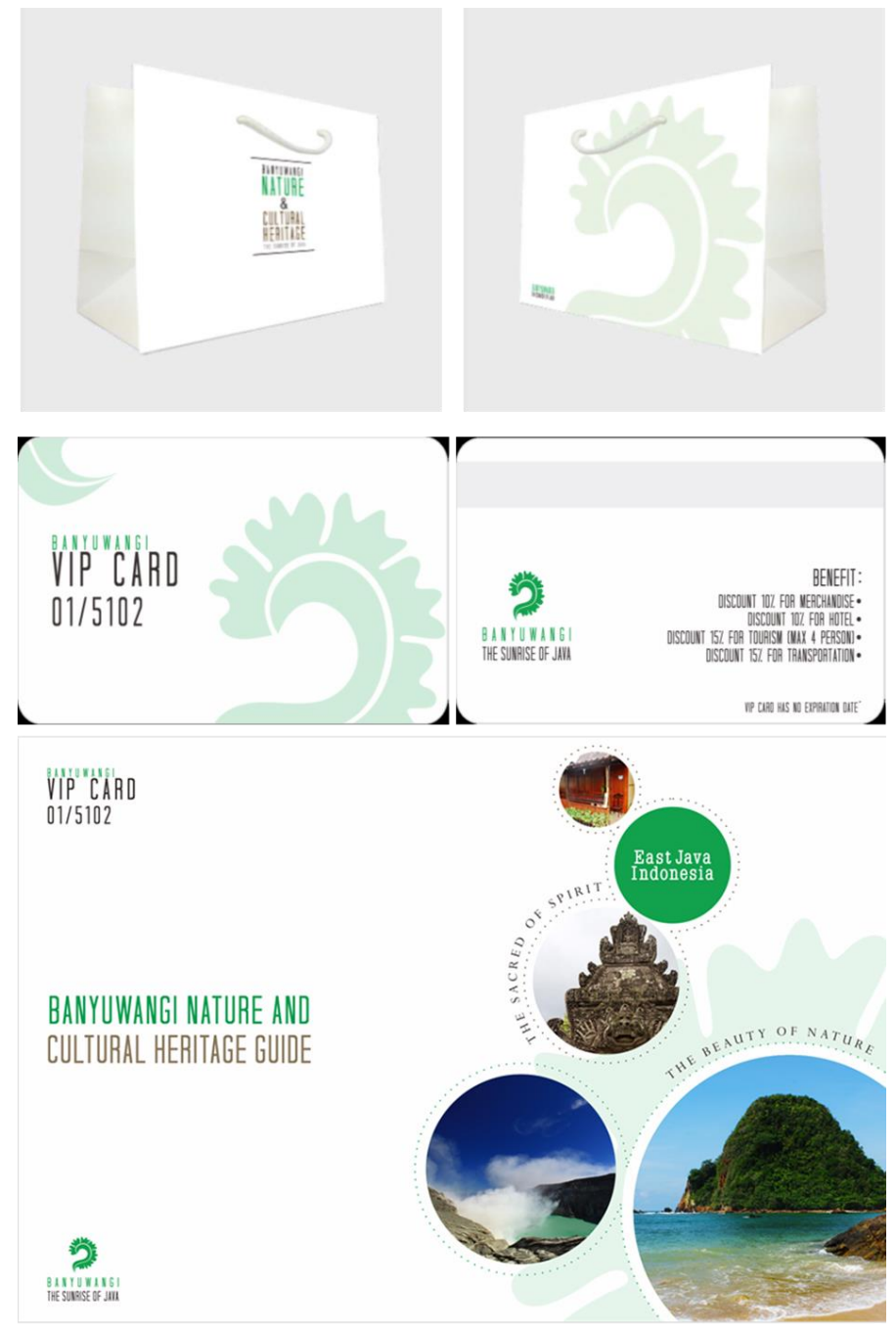

Gambar 10. Desain final media pendamping paperbag, vip card \& packaging. Sumber: Dokumentasi penulis
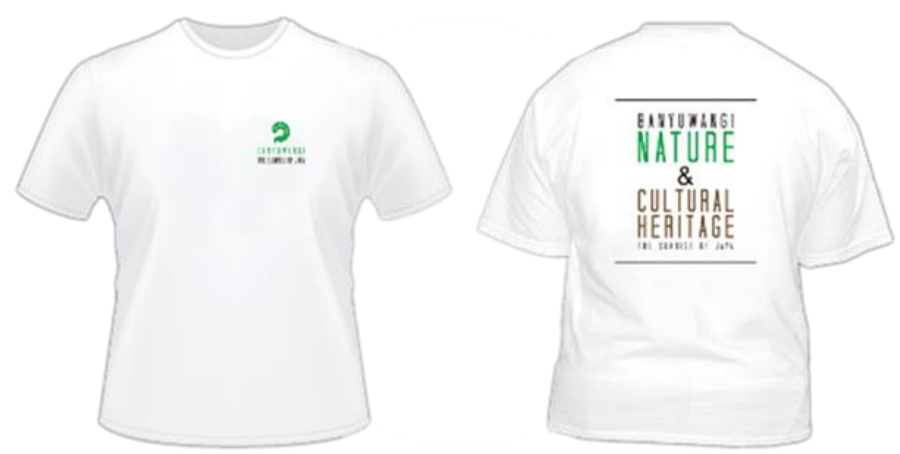

Gambar 11. Desain final media promosi kaos.

Sumber: Dokumentasi penulis 

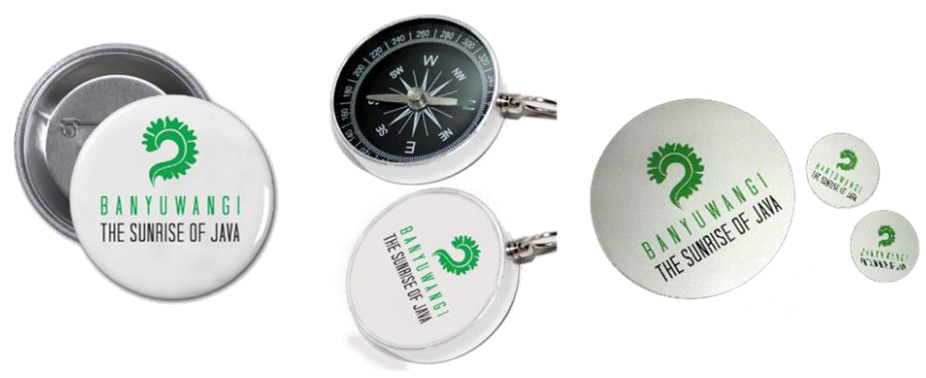

Gambar 12. Desain final media promosi sticker, compass \& pin. Sumber: Dokumentasi penulis

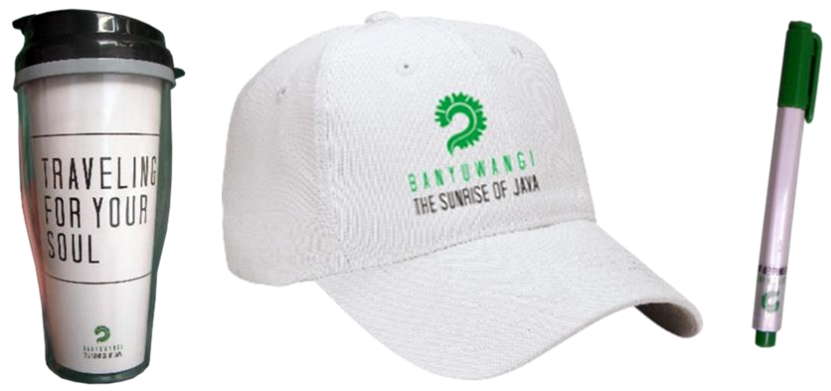

Gambar 13. Desain final media promosi tumbler, topi \& ballpoint Sumber: Dokumentasi penulis
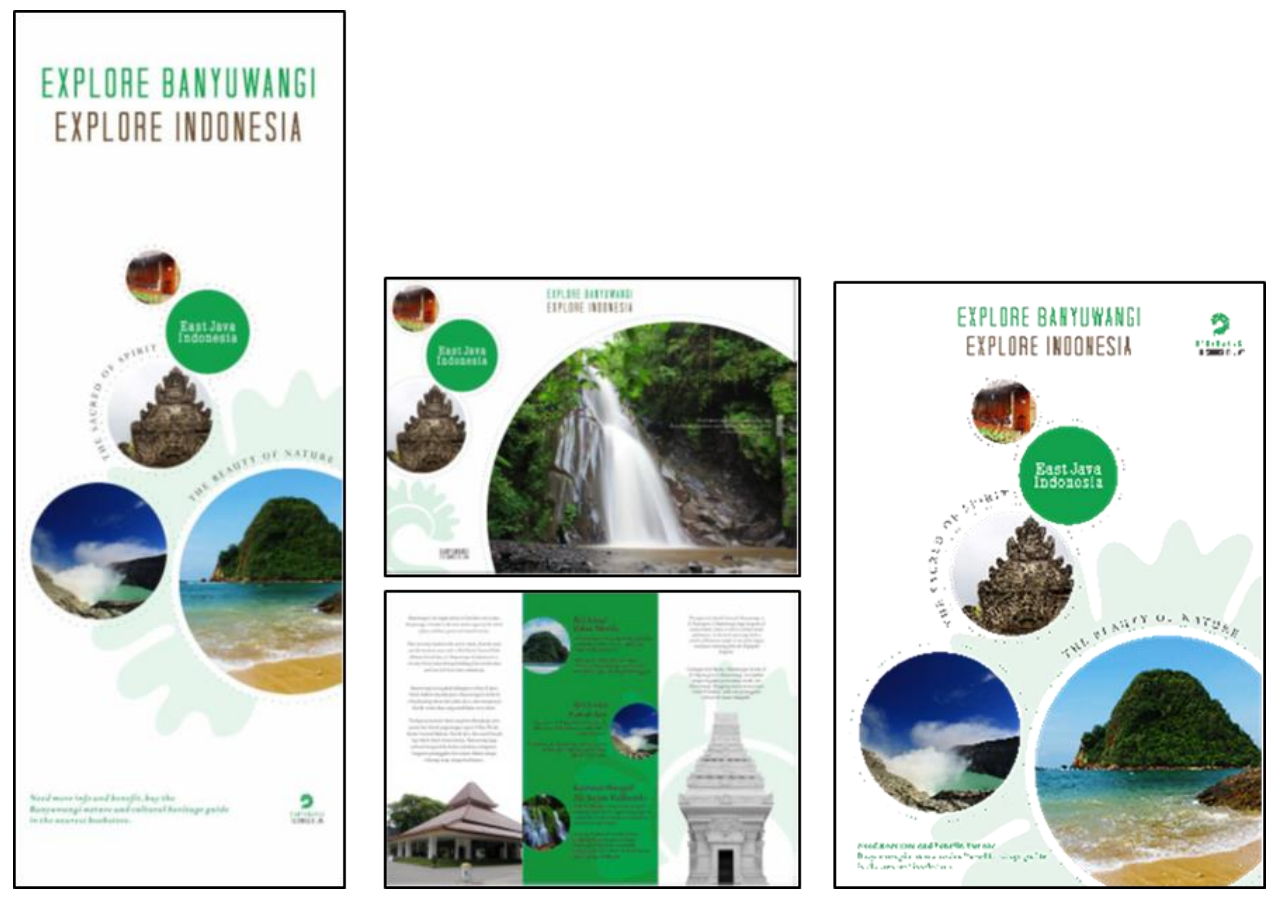

Gambar 14. Desain final media promosi banner, brosur \& poster. Sumber: Dokumentasi penulis 


\section{SIMPULAN DAN SARAN}

\section{Simpulan}

Sebagai Kabupaten yang memiliki kekayaan akan keindahan objek wisata alam dan cagar budaya membutuhkan media panduan wisata yang informatif, praktis dan menarik dalam melakukan pengenalan serta promosi. Selain itu, media panduan wisata haruslah dapat mencerminkan karakteristik yang dimiliki Banyuwangi dan berbeda dari para pesaing sehingga media panduan wisata yang dimiliki Banyuwangi mudah dikenali dan diingat oleh masyarakat.

Media utama yang penulis rancang dalam perancangan ini terdiri dari buku panduan wisata alam, buku panduan wisata cagar budaya dan e-book yang menggunakan teknik fotografi. Media pelengkap yang penulis rancang terdiri dari peta, pembatas buku, packaging, paper bag, vip card. Media pelengkap tersebut digunakan sebagai pendukung dalam perancangan ini. Dengan adanya media pelengkap maka lebih mempermudah para wisatawan dalam kegiatan berwisata. Media promosi yang penulis rancang terdiri dari brosur, poster dan stiker. Media utama dikemas dalam satu kemasan dengan media pelengkap dan beberapa merchandise. Media promosi yang penulis rancang terdiri dari brosur dan poster. Merchandise yang dirangcang terdiri dari ballpoint, keychain, pin, mini bag, kaos, tumbler dan topi.

Media panduan wisata alam dan cagar budaya tersebut penulis rancang dengan menggunakan konsep Informative, Attractive, Useful dan didasari oleh prinsip-prinsip desain yang ada, agar media tersebut dapat memperkenalkan sekaligus mempromosikan objek-objek wisata yang ada di Banyuwangi. Selain itu media tersebut dirancang supaya mempermudah para wisatawan untuk berwisata ke Banyuwangi.

\section{Saran}

Setelah melewati proses perancangan media panduan wisata alam dan cagar budaya Banyuwangi, penulis dapat memberikan saran bagi orang-orang yang akan melakukan perancangan sebagai berikut: 1) Untuk menghasilkan sebuah karya desain komunikasi visual yang baik diperlukan adanya konsep perancangan yang baik sebagai dasarnya, sehingga sangatlah penting bagi seorang desainer untuk memiliki pengetahuan yang mendalam mengenai subjek dan objek yang dirancang 
serta teori-teori desain komunikasi visual yang digunakan dalam perancangan; 2) Dalam melakukan perancangan media panduan wisata alam dan cagar budaya Banyuwangi hendaklah mengacu pada karakteristik unik dari subjek perancangan, serta mempertimbangkan pesaing dan apa yang diinginkan oleh target audiens dari subjek perancangan. Sehingga perancangan yang dilakukan mampu menghasilkan media panduan wisata alam dan cagar budaya yang informatif, praktis dan menarik.

\section{DAFTAR PUSTAKA}

Goeldner, Charles R. (1999). Tourism: Principles, Practices, Philosophies. Canada: John Wiley \& Sons, Inc.

Jpnn.com. (2014). Banyuwangi Luncurkan Perda Perlindungan Cagar Budaya. Diakses pada tanggal 20 Desember 2014 dari http://www.jpnn.com/news/banyuwangi-luncurkan-perda-perlindungancagar-budaya?page $=2$.

Rachmawati, Ira. (2013). Benda Cagar Budaya Dipamerkan di Banyuwangi. Diakses pada tanggal 18 Desember 2014 dari http://travel.kompas.com/read/2013/10/30/1028060/Benda.Cagar.Budaya.Di pamerkan.di.Banyuwangi.

Republik Indonesia. (1990). Undang Undang No 5 tahun 1990 tentang Konservasi Sumberdaya Alam Hayati Dan Ekosistemnya.

Republik Indonesia. (2010). Undang-Undang Republik Indonesia Nomor 11 Tahun 2010 Tentang Cagar Budaya.

Yoeti, O.A. (1996). Pengantar Ilmu Pariwisata. Bandung: Angkasa Offset. 